\title{
Article
}

\section{Prevalence of Hypovitaminosis $C$ and its Relationship with Frailty in Older Hospitalised Patients: A Cross-Sectional Study}

\author{
Yogesh Sharma ${ }^{1,2, * \mathbb{C}}$, Alexandra Popescu ${ }^{3}$, Chris Horwood ${ }^{4}$, Paul Hakendorf ${ }^{4}$ and Campbell Thompson ${ }^{5}(\mathbb{D}$ \\ 1 College of Medicine \& Public Health, Flinders University, Adelaide 5042, Australia \\ 2 Department of General Medicine, Division of Medicine, Cardiac \& Critical Care, Flinders Medical Centre, \\ Adelaide 5042, Australia \\ 3 Department of Geriatrics \& Rehabilitation, Flinders Medical Centre, Adelaide 5042, Australia; \\ alexandra.popescu@sa.gov.au \\ 4 Department of Clinical Epidemiology, Flinders Medical Centre, Adelaide 5042, Australia; \\ chris.horwood@sa.gov.au (C.H.); paul.hakendorf@sa.gov.au (P.H.) \\ 5 Discipline of Medicine, The University of Adelaide, Adelaide 5005, Australia; \\ campbell.thompson@adelaide.edu.au \\ * Correspondence: yogesh.sharma@flinders.edu.au; Tel.: +61-8-82046694
}

\section{check for} updates

Citation: Sharma, Y.; Popescu, A.; Horwood, C.; Hakendorf, P.; Thompson, C. Prevalence of Hypovitaminosis $C$ and its Relationship with Frailty in Older Hospitalised Patients: A Cross-Sectional Study. Nutrients 2021, 13, 2117. https://doi.org/10.3390/ nu13062117

Academic Editors: Anitra Carr and Adrian Gombart

Received: 26 May 2021

Accepted: 17 June 2021

Published: 20 June 2021

Publisher's Note: MDPI stays neutral with regard to jurisdictional claims in published maps and institutional affiliations.

Copyright: (c) 2021 by the authors. Licensee MDPI, Basel, Switzerland. This article is an open access article distributed under the terms and conditions of the Creative Commons Attribution (CC BY) license (https:// creativecommons.org/licenses/by/ $4.0 /)$.

\begin{abstract}
Frailty is common in older hospitalised patients and may be associated with micronutrient malnutrition. Only limited studies have explored the relationship between frailty and vitamin C deficiency. This study investigated the prevalence of vitamin $C$ deficiency and its association with frailty severity in patients $\geq 75$ years admitted under a geriatric unit. Patients $(n=160)$ with a mean age of $84.4 \pm 6.4$ years were recruited and underwent frailty assessment by use of the Edmonton Frail Scale (EFS). Patients with an EFS score $<10$ were classified as non-frail/vulnerable/mildly frail and those with $\geq 10$ as moderate-severely frail. Patients with vitamin C levels between 11-28 $\mu \mathrm{mol} / \mathrm{L}$ were classified as vitamin $C$ depleted while those with levels $<11 \mu \mathrm{mol} / \mathrm{L}$ were classified as vitamin $\mathrm{C}$ deficient. A multivariate logistic regression model determined the relationship between vitamin $\mathrm{C}$ deficiency and frailty severity after adjustment for various co-variates. Fifty-seven (35.6\%) patients were vitamin C depleted, while 42 (26.3\%) had vitamin C deficiency. Vitamin C levels were significantly lower among patients who were moderate-severely frail when compared to those who were non-frail/vulnerable/mildly frail $(p<0.05)$. After adjusted analysis, vitamin $C$ deficiency was 4.3-fold more likely to be associated with moderate-severe frailty (aOR 4.30, 95\% CI 1.33-13.86, $p=0.015$ ). Vitamin C deficiency is common and is associated with a greater severity of frailty in older hospitalised patients.
\end{abstract}

Keywords: frailty; vitamin C deficiency; elderly; hospitalisation

\section{Introduction}

Worldwide, with an aging population, there is a global interest in aging processes and age-related diseases. Frailty represents a precise measurement of aging-related symptoms and constitutes a syndrome taking into account physical disability, low energy levels and loss of cognition [1]. Frailty is associated with poor clinical outcomes such as falls, poor health related quality of life (HRQoL), nursing home placement and death [1,2]. This syndrome has been shown to be potentially preventable and can be reversed if targeted in earlier stages [3]. The prevalence of frailty in acutely hospitalised older patients can be up to $48 \%$ [4] while as many as $84 \%$ of patients admitted to a geriatric evaluation and management (GEM) unit may be frail [3].

While protein energy malnutrition is a major risk factor for the development of frailty, the role of micronutrient deficiencies in the development of frailty is less clear [5]. Micronutrient deficiencies are far more common and often precede development of overt malnutrition [6]. Micronutrient deficiencies can potentially increase the risk of frailty 
through multiple mechanisms such as an increase in oxidative stress and inflammation, the impairment of bone and muscle metabolism and a reduction in immunity [7]. Vitamin C is a powerful antioxidant and $40 \%$ of the total body pool is present in the skeletal muscles [8].

Previous studies suggest that micronutrient deficiency (especially vitamin D and vitamin B12 deficiency) may be associated with frailty, but the relationship between biochemical vitamin $C$ deficiency and frailty is unclear [7]. To date, only limited studies $[9,10]$ have explored the relationship between frailty and vitamin $C$ deficiency. The aims of the current research were to determine the prevalence of vitamin $C$ deficiency in older frail patients admitted to a GEM unit and explore the relationship between vitamin $C$ deficiency and severity of frailty. The hypothesis for this research was that older hospitalised patients will have a high prevalence of vitamin $C$ deficiency and low vitamin $C$ levels will be associated with a greater severity of frailty.

Outcomes: The primary outcome for this study was to determine the prevalence of biochemical vitamin C deficiency in older patients admitted to a GEM unit, and the secondary outcome was to determine whether biochemical vitamin $\mathrm{C}$ deficiency is a predictor of severe frailty.

\section{Materials and Methods}

Patients $\geq 75$ years who were admitted to the GEM unit of Flinders Medical Centre between May-December 2020 were recruited by convenience sampling in this research. A written informed consent was obtained from the participants, and in the case of cognitive impairment, consent was obtained from the legal guardian. A member of the research team approached the participants and provided them with a participant information sheet in addition to verbal information about the research project. The participants were given sufficient time to read and discuss their participation with their caretakers as well as the treating medical team. If the participants were agreeable, they were asked to sign a consent form.

The exclusion criteria were a lack of a valid consent, patients receiving end of life care and those on vitamin $C$ replacement. Ethical approval for this study was granted by the Southern Adelaide Human Clinical Research Ethics Committee, and this study was registered with the Australia and New Zealand Clinical Trial Registry.

Frailty assessment was performed by use of the Edmonton Frail Scale (EFS). The EFS is a valid and reliable instrument for the identification of frailty in hospitalised patients and predicts clinical outcomes [11,12]. The EFS contains nine components and is scored out of 17. Individual components include: cognition, general health status, self-reported health, functional independence, social support, polypharmacy, mood, continence and functional performance. The component scores are summed, and the following cut-off scores are used to classify the severity of frailty: not frail (0-5), apparently vulnerable (6-7), mild frailty (8-9), moderate frailty (10-11) and severe frailty (12-17). Comorbidities were assessed by use of the Charlson comorbidity index (CCI), which is a score based on various diseases such as myocardial infarction, congestive heart failure, diabetes, renal failure, cerebrovascular disease, peripheral vascular disease, chronic lung disease, liver disease, peptic ulcer and acquired immunodeficiency syndrome (AIDS) and is a valid and reliable method of measuring comorbidity [13,14].

The physical functioning was assessed by use of the Short Physical Performance Battery (SPPB) test, which is a validated measure of lower limb function in older adults and uses tasks that mimics activities of daily living [15]. This test comprises of three subtests: standing balance, four-metre gait speed (4 m GS) and five sit-to-stand (5 STS) tests. The subtests are scored from $0-4$ and summated to give a total SPPB score (ranging from 0-12) with higher scores being indicative of a better physical performance [16]. Fall risk was assessed using the Timed Up and Go (TUG) test [17]. In this test, the patient is asked to rise from a seated position, walk 3 metres, turn around and return and sit in the starting point chair while timed. Patients who are unable to complete this test in $<12$ seconds are considered to have at high risk of falls [18]. 
Cognitive status was determined by the use of the Mini Mental State Examination (MMSE) [19] and mood was assessed by using the Geriatric Depression Scale (GDS) [20]. The GDS is a 15-item tool that has been validated for screening depressive symptoms in the older population, including acutely hospitalised medical patients [21,22]. Nutrition risk was determined by use of the Malnutrition Universal Screening Tool (MUST) [23] and the HRQoL was determined by the European Quality of Life 5-Dimension 5-Level (EQ5D-5L) questionnaire [24]. The activities of daily living (ADL) were assessed by use of the Hospital Admission Risk Profile (HARP) score [25], which predicts patients at high risk of discharge to a facility.

Fasting venous blood samples were drawn by a trained phlebotomist. The sample for vitamin $C$ level was wrapped in an aluminium foil and immediately placed on ice for transport to a central laboratory. High performance liquid chromatography (HPLC) was used to determine vitamin C levels. HPLC has been previously validated for the rapid and specific measurement of vitamin C [26]. Plasma vitamin C levels correlate with dietary vitamin $C$ intake and unlike leucocyte vitamin $C$ levels, plasma vitamin $C$ levels are not influenced by changes in the white blood cell (WBC) count and thus represent an accurate measure of vitamin C status [26,27]. According to Johnston's criteria [28], vitamin C levels $\geq$ $28 \mu \mathrm{mol} / \mathrm{L}$ are classified as normal, $11-27 \mu \mathrm{mol} / \mathrm{L}$ as vitamin $C$ depletion and $<11 \mu \mathrm{mol} / \mathrm{L}$ as vitamin C deficiency. For this study, patients with vitamin C levels $\geq 28 \mu \mathrm{mol} / \mathrm{L}$ were defined as vitamin $C$ replete and all those with levels $<28 \mu \mathrm{mol} / \mathrm{L}$ as hypovitaminosis $\mathrm{C}$. Vitamin C levels were also divided into quintiles, and we compared clinical outcomes such as length of hospital stay (LOS), in hospital mortality and readmissions within 30 days of hospital discharge in different quintiles. In addition, the phlebotomist collected venous blood samples for determination of haemoglobin, creatinine, C-reactive protein (CRP), albumin, vitamin D and vitamin B12 levels. The technique of spectrophotometry was used to determine haemoglobin, creatinine and albumin levels, while rapid immunoassays, Roche Diagnostics (www.roche.com), determined the C-RP, vitamin D and vitamin B12 levels in the central laboratory.

\section{Statistics}

The normality of the data was assessed by visual inspection of histograms. Continuous variables were assessed by use of the Student's t-tests or rank sum tests and categorical variables by Chi squared statistics or Fisher's exact test as appropriate. A Kruskal-Wallis $\mathrm{H}$ test was used to compare the LOS in different quintiles of vitamin C. Patients with EFS scores $\geq 10$ were classified as moderately to severely frail while those with EFS scores $<10$ as non-frail, vulnerable or mildly frail. We correlated vitamin C levels with EFS scores. A logistic regression analysis was used to determine whether vitamin $C$ deficiency was associated with a greater severity of frailty after adjustment for the following co-variates: age, sex, Charlson index, smoking status, MUST score, MMSE, GDS, fruit and vegetable intake, socioeconomic status (determined by annual income), HARP score, vitamin D and vitamin B12 levels. We determined any effect modification by use of interaction terms with vitamin D and vitamin B12 in the model. We performed a sensitivity analysis and determined the bias-corrected estimates using the jackknife resampling method as suggested by Nemes et al [29]. Prediction graphs with 95\% confidence intervals were plotted to determine whether vitamin $C$ levels were associated with increasing severity of frailty using the marginsplot command in STATA. Polypharmacy was defined as being on five or more medications.

The sample size was based on a recent study [30], which suggested a high prevalence $(>70 \%)$ of biochemical vitamin $C$ deficiency in hospitalised patients. Assuming a prevalence of $70 \%$ and a precision level of $10 \%$, the calculated sample size for this study was 140 , and assuming $10 \%$ missing data, a total of 160 patients were deemed sufficient for this study. All statistical analyses were conducted using Stata version 17.0 (StataCorp, College Station, TX, USA). 


\section{Results}

Six hundred and three patients were admitted under the GEM unit between May and December 2020, of whom, 176 patients were approached by convenience sampling for participation, and 160 patients were recruited for this study while 16 patients were excluded because of various reasons (Figure 1).

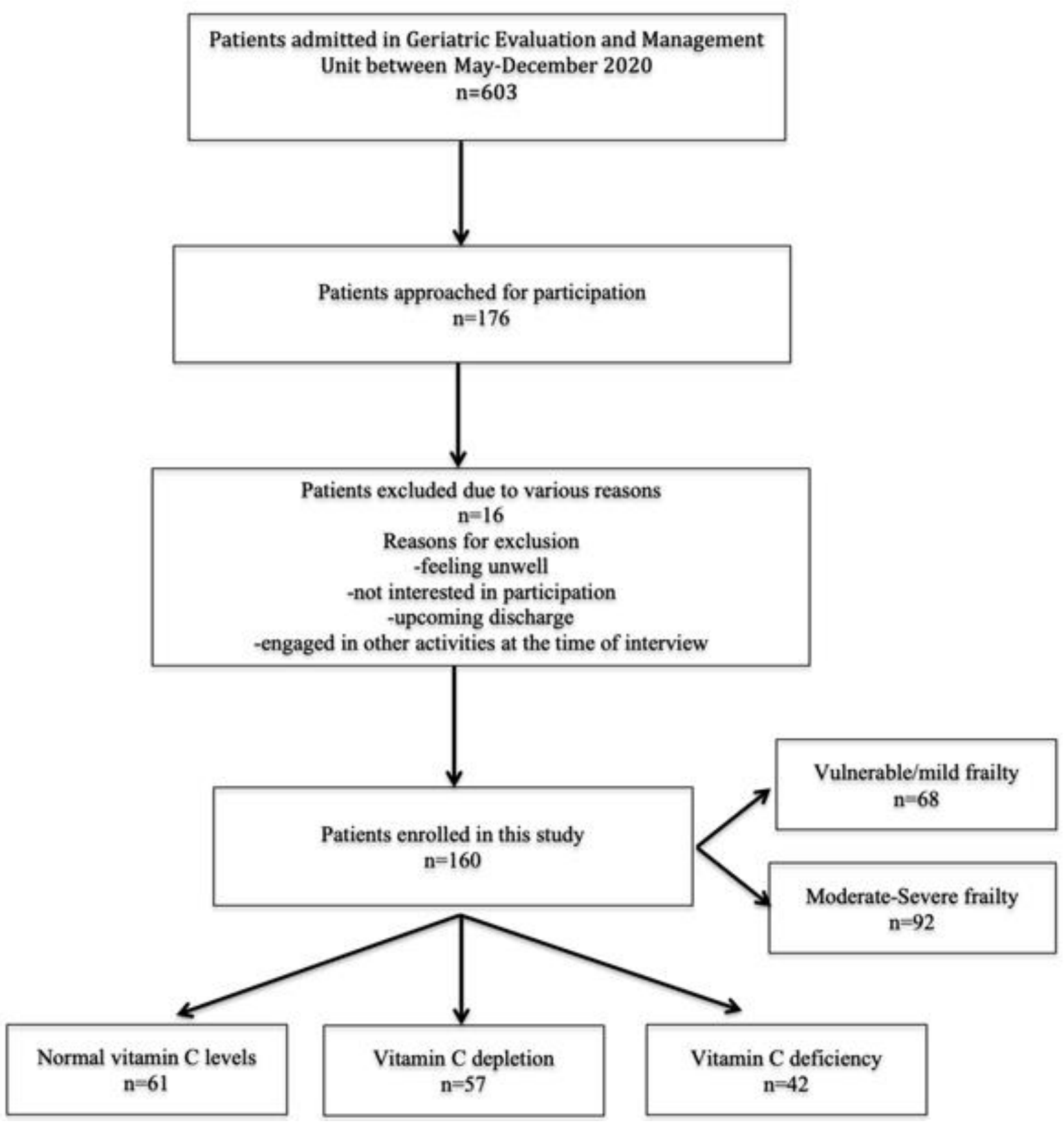

Figure 1. Study flow diagram.

There was no missing data and vitamin $C$ results were available for all the participants. The mean (SD) age was 84.4 (6.4) years (range: 75-105 years) and 96 (60\%) were females. All patients were residing in their own homes and $78(48.7 \%)$ were living with their partners. The mean Charlson index was 8.4 (2.6), and the majority of patients were on polypharmacy $130(81.3 \%)$ and many were admitted with falls as the principal diagnosis $(69,43.1 \%)$. The mean (SD) vitamin C levels were $26.8(23.0) \mu \mathrm{mol} / \mathrm{L}$, (range: 3-148). The median (IQR) time 
from hospital admission to the collection of vitamin C sample was $4(4,4)$ days. According to Johnston's criteria, $61(38.1 \%)$ had a normal vitamin C status, $57(35.6 \%)$ were vitamin C depleted and while 42 (26.3\%) had vitamin C deficiency (Figure 1). Overall, 99 (61.9\%) were classified as having hypovitaminosis C, i.e., vitamin C levels below $28 \mu \mathrm{mol} / \mathrm{L}$. The mean (SD) EFS score was 9.8 (2.1) (range: 5-16). Sixty-eight (42.5\%) patients were classified as non-frail/vulnerable or with mild frailty $(\mathrm{EFS}<10)$ and $92(57.5 \%)$ were classified with moderate to severely frailty (EFS $\geq 10$ ). Patients who had moderate to severe frailty were more likely to be older, with a higher Charlson index, a lower mean MMSE score and were more likely to be depressed than those who were non-frail/vulnerable or had mild frailty (Table 1). Patients with moderate to severe frailty had poor physical functioning, as reflected by a longer TUG test and lower SPPB scores, and had a poorer health related quality of life, as reflected by the lower EQ5D index when compared to those who were non-frail/vulnerable or had mildly frailty (Table 1). Both LOS and in-hospital mortality was significantly higher among patients who were moderately to severely frail in comparison with the non-frail/vulnerable/mildly frail group. However, there was no difference in 30-day readmissions between the two groups.

Table 1. Characteristics of vulnerable/mildly frail patients compared to moderate/severely frail patients.

\begin{tabular}{|c|c|c|c|}
\hline Variable & $\begin{array}{l}\text { Non-Frail/Vulnerable/Mild } \\
\text { Frailty }\end{array}$ & Moderate-Severe Frailty & $p=$ Value \\
\hline Number (\%) & $68(42.5)$ & $92(57.5)$ & \\
\hline Age, mean (SD) & $82.8(5.7)$ & $85.7(6.7)$ & 0.004 \\
\hline Sex female, $n(\%)$ & $39(57.4)$ & $57(61.9)$ & 0.557 \\
\hline Charlson index mean (SD) & $7.8(2.5)$ & $8.8(2.6)$ & 0.001 \\
\hline Medications mean (SD) & $6.9(3.9)$ & $7.9(3.3)$ & 0.070 \\
\hline Residence home alone $n(\%)$ & $32(47.1)$ & $50(54.4)$ & 0.362 \\
\hline Education diploma/university $n(\%)$ & $31(45.6)$ & $34(36.9)$ & 0.272 \\
\hline Income $<40 \mathrm{k} /$ year & $34(50.8)$ & $60(65.2)$ & 0.067 \\
\hline Medications mean (SD) & $6.9(3.9)$ & $7.9(3.3)$ & 0.070 \\
\hline MMSE mean (SD) & $25.8(3.4)$ & $23.8(3.2)$ & $<0.001$ \\
\hline Smokers $n(\%)$ & $41(60.3)$ & $51(55.4)$ & 0.539 \\
\hline GDS mean (SD) & $3.5(2.1)$ & $5.2(3.1)$ & $<0.001$ \\
\hline MUST score mean (SD) & $0.86(1.1)$ & $0.99(1.2)$ & 0.511 \\
\hline Fruits/Vegetable intake/day mean (SD) & $1.3(0.6)$ & $1.2(0.6)$ & 0.187 \\
\hline HARP score mean (SD) & $2.4(1.2)$ & $3.5(0.6)$ & $<0.001$ \\
\hline TUG score in seconds mean (SD) & $25.3(15.4)$ & $40.3(20.5)$ & $<0.001$ \\
\hline Vitamin C $\mu \mathrm{mol} / \mathrm{L}$ mean (SD) & $31.8(24.4)$ & $22.9(21.4)$ & 0.015 \\
\hline Hypovitaminosis $\mathrm{C} n(\%)$ & $37(54.4)$ & $62(67.4)$ & 0.095 \\
\hline Vitamin C deficient $n(\%)$ & $11(16.2)$ & $31(33.7)$ & 0.013 \\
\hline Vitamin D nmol/L mean (SD) & $62.9(27.3)$ & $72.4(33.4)$ & 0.058 \\
\hline Vitamin B12 pmol/L mean (SD) & $442.9(300.7)$ & $502.5(351.8)$ & 0.262 \\
\hline Albumin g/L mean (SD) & $35.6(30.0)$ & $31.3(5.2)$ & 0.180 \\
\hline EFS scores mean (SD) & $7.7(1.1)$ & $11.3(1.3)$ & $<0.001$ \\
\hline SPPB scores total mean (SD) & $5.5(2.8)$ & $2.7(2.3)$ & $<0.001$ \\
\hline EQ5D index mean (SD) & $0.78(0.13)$ & $0.68(0.16)$ & $<0.001$ \\
\hline LOS median (IQR) & $11.5(14)$ & $22.7(17)$ & 0.004 \\
\hline In-hospital mortality $n(\%)$ & 0 & $7(7.6)$ & 0.02 \\
\hline 30-day readmissions $n(\%)$ & $15(22.1)$ & $20(21.7)$ & 0.961 \\
\hline
\end{tabular}

SD, Standard Deviation; MMSE, Mini Mental State Examination; GDS, Geriatric Depression Scale; MUST, Malnutrition Universal Screening Tool; HARP, Hospital Admission Risk Profile; TUG, Timed Up and Go Test; EFS, Edmonton Frail Scale; SPPB, Short Physical Performance Battery; EQ5D, European Quality of Life questionnaire; LOS, Length of Hospital Stay; IQR, Interquartile Range.

There was no difference in the median (IQR) time in days from hospital admission to the collection of the vitamin $C$ sample between the moderate to severely frail and the non-frail/vulnerable/mildly frail groups $(4(3,4)$ vs. $4(4,4)$ days, $p>0.05$, respectively). The mean (SD) vitamin C levels were significantly lower among patients who had moderate to severe frailty when compared to those who were non-frail/vulnerable or had mild frailty 
$(22.9(21.4)$ vs. $31.8(24.4), p=$ value $=0.015)$. There was a weak negative correlation between vitamin C levels and EFS score (correlation coefficient $=-0.14, p=0.081$ ). The logistic regression analysis suggested that patients with vitamin $C$ deficiency were more likely to be associated with moderate to severe frailty after adjustment for age, sex, Charlson index, smoking status, MUST score, MMSE, GDS, fruit and vegetable intake, socioeconomic status, HARP score, vitamin D and vitamin B12 levels when compared to those who were non-frail/vulnerable or mildly frail (aOR 4.30, 95\% CI 1.33-13.86, $p==0.015$ ) (Table 2). The senstivity analysis using the jackknife resampling method confirmed these estimates (aOR 4.30, SE 3.01, 95\% CI 1.07-17.12, $p=0.039)$. There was no effect modification $(p>0.05)$ by use of interaction terms with vitamin B12 and vitamin D. The margins plot indicated that low plasma vitamin $C$ levels predicted moderate to severe frailty (Figure 2). Clinical outcomes such as LOS, inhospital mortality and 30-day readmissions were not significantly different according to different vitamin C quintiles (> 0.05).

Table 2. Logistic regression model showing adjusted odds ratios in moderate-severely frail patients compared to non-frail/vulnerable/mildly frail patients with normal vitamin C status as the baseline.

\begin{tabular}{cccc}
\hline Variable. & aOR & $\mathbf{9 5 \%} \mathbf{C I}$ & $p$ Value \\
\hline Vitamin C deficiency & 4.30 & $1.33-13.86$ & 0.015 \\
Vitamin C depletion & 1.83 & $0.66-5.08$ & 0.243 \\
Age & 0.94 & $0.87-1.02$ & 0.158 \\
Sex male & 0.95 & $0.34-2.673$ & 0.924 \\
Charlson index & 1.03 & $0.85-1.27$ & 0.715 \\
Smokers & 0.68 & $0.28-1.66$ & 0.395 \\
MUST score & 1.17 & $0.77-1.78$ & 0.463 \\
MMSE score & 0.89 & $0.78-1.02$ & 0.104 \\
GDS score & 1.33 & $1.09-1.61$ & 0.004 \\
Fruits /Vegetable intake & 0.94 & $0.84-1.06$ & 0.350 \\
HARP score & 4.78 & $2.43-9.40$ & $<0.001$ \\
Income <40k/year & 1.67 & $0.63-4.44$ & 0.302 \\
Creatinine & 0.99 & $0.98-1.00$ & 0.069 \\
Vitamin D levels & 1.01 & $0.99-1.02$ & 0.281 \\
Vitamin B12 levels & 1.00 & $0.99-1.00$ & 0.344 \\
\hline
\end{tabular}

aOR, adjusted odds ratio; MUST, Malnutrition Universal Screening Tool; MMSE, Mini Mental State Examination GDS, Geriatric Depression Scale; HARP, Hospital Admission Risk Profile.

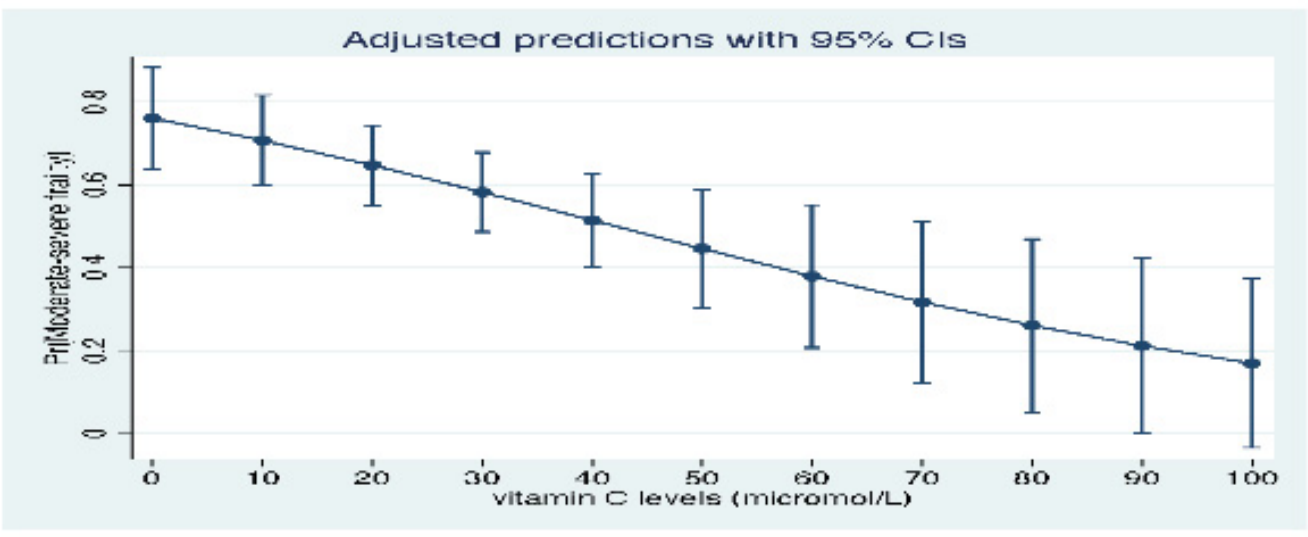

Figure 2. Prediction of frailty severity according to vitamin $C$ status.

\section{Discussion}

The results of this study suggest that there is a high prevalence of hypovitaminosis $\mathrm{C}$ in older hospitalised patients with a quarter of patients being vitamin $\mathrm{C}$ deficient. Patients with moderate to severe frailty demonstrated a significantly lower vitamin $C$ levels when compared to those who were non-frail/vulnerable or were mildly frail even after adjustment for various co-variates. 
The prevalence of hypovitaminosis $\mathrm{C}$ in this study was $61.9 \%$, which confirms the findings of a recent Australian study [30] that also found that a high proportion $(>70 \%)$ of acutely hospitalised older patients were vitamin C depleted. Similary, a study [31] on patients who were referred for an elective surgical procedure found that $43.1 \%$ had vitamin $\mathrm{C}$ depletion. The slightly lower prevalence of vitamin $\mathrm{C}$ deficiency in the above study could be related to the lower mean age (62 (15.3) years vs. $84.4(6.4)$ years) of patients in this study because two previous studies $[32,33]$ have suggested that vitamin C levels decline with aging.

Previous studies indicate that older people have inadequate intake of micronutrients such as vitamin A, D, E, B6, B12, folate and zinc [34-36]. The intake of vitamin C and carotenoids may also decline with older age $[37,38]$. Older people are at a high risk of micronutrient malnutrition due to a range of factors including anorexia of ageing and social factors, such as difficulty with shopping or the preparation of meals due to physical disabilities $[32,39,40]$. Our study also found that the risk of malnutrition, as determined by the MUST score, was not significantly higher among patients who had hypovitaminosis C. These findings corroborrate previous evidence that micronutrient deficiencies in older patients may exist even without overt signs of clinical malnutrition [7].

This study indicates that vitamin $C$ deficiency is associated with a greater severity of frailty in older hospitalised patients. This could be related to a higher degree of oxidative stress in ascorbic acid deficient skeletal muscles leading to muscle dysfunction. Previous evidence indicates that there is a relationship between oxidative stress and frailty [41,42]. Reactive oxygen species (ROS) are continuously produced in skeletal muscles [43], and the production of ROS is increased by exercise, which promotes oxidative stress due to induction of potentially damaging biomolecules, such as proteins, lipids and DNA [44]. Recent research shows that physical inactivity also induces ROS production and may lead to muscle atrophy $[45,46]$. Furthermore, elevated ROS levels have been found in subjects with ageing-related sarcopenia and muscular diseases [42,47].

In addition, vitamin $C$ is involved in the synthesis of carnitine and collagen [48]. While carnitine is required for the metabolism of long chain fatty acids during physical activity, collagen is a key structural component of skeletal muscles and tendons $[49,50]$. Animal studies have suggested that ascorbic acid deficiency in skeletal muscles caused muscle atrophy, concomitant with a high expression of muscle atrophy-related genes with a reduction in physical performance [8,51]. Interestingly, ascorbic acid supplementation restored physical performance and reduced the expression of muscle atrophy-related genes [8].

Limited clinical studies have determined a relationship between vitamin C deficiency and frailty. A Japanese study [9] involving 655 community dwelling older women (mean (SD) age 75.4 (4.1) years) suggested that plasma vitamin C levels positively correlate with muscle strength and physical performance measured in terms of handgrip strength, length of time standing on one leg and gait speed. Similarly, a study in the UK [52] involving 628 community dwelling patients aged $63-73$ years found that a higher vitamin $C$ intake was associated with a better physical performance measured by short chair rising time. Another European study [48], which included $>13000$ men and women aged 42-82 years, found that both dietary intake and plasma vitamin $C$ levels had a positive association with fat-free mass (FFM) using bioelectrical impedance analysis.

Fruits and vegetables are rich sources of antioxidants including carotenoids, flavonoids, vitamin $C$ and other polyphenols [53]. Research suggests that a higher intake of fruits and vegetables is protective against inflammation, cardiovascular disease and mortality [54-56]. It is also possible that in addition to the high oxidant stress, vitamin C deficiency also indirectly contributes to the increasing severity of frailty due to the higher prevalence of cardiovascular diseases in this population.

Although previous studies have indicated negative health outcomes with vitamin C deficiency $[57,58]$, this was not evident in our study and clinical outcomes such as LOS, mortality and readmissions were similar across different vitamin $C$ quintiles. Our 
study was, however, not powered to detect clinical outcomes. In addition, evidence to date is unconvincing that vitamin $C$ supplementation is beneficial in improving either cardiovascular outcomes [57] or sepsis-related mortality [10,59]. However, the evidence is of low quality because of limitations such as the use of a small sample size and shorter duration of interventions. It is possible that vitamin $C$ supplementation will be more effective for a subgroup of patients such as older people, those with a higher baseline cardiovascular risk and those with lower baseline vitamin $C$ status. Future trials are needed avoiding the abovementioned limitations and targeting subgroup of population who are at a high risk of vitamin $C$ deficiency to clarify beneficial effects of vitamin $C$ supplementation.

\section{Limitations}

This study used convenient sampling for recruitment of participants, and it is possible that the sample may not be a true representative of patients who were admitted under the GEM unit. In addition, the sample is not representative of the general elderly population but of those individuals who were referred to a geriatric unit and were therefore more likely to have geriatric syndromes. The findings of this study cannot be used to suggest causality because of the cross-sectional design of the study. We were unable to quantify the intake of energy and protein of our patients in this study. There was a delay in obtaining vitamin C levels immediately following hospitalisation because micronutrient levels decline during hospitalisation due to a range of factors such as anorexia, inflammation and polypharmacy [60,61].

\section{Conclusions}

This study confirms that a high prevalence of hypovitaminosis $C$ in older hospitalised patients and vitamin $C$ deficiency is associated with a greater severity of frailty. Further studies are needed to confirm this association and to determine whether vitamin $C$ replacement may be beneficial in prevention or reversal of frailty.

Author Contributions: Conceptualization, Y.S. and C.T.; methodology, Y.S.; software, Y.S., C.H. and P.H.; validation, Y.S. and A.P.; formal analysis, Y.S.; investigation, Y.S.; resources, Y.S.; data curation, Y.S., A.P. and C.H.; writing—original draft preparation, Y.S.; writing—review and editing, Y.S. and C.T.; visualization, Y.S.; supervision, Y.S. and C.T.; project administration, Y.S. All authors have read and agreed to the published version of the manuscript.

Funding: This research received no external funding.

Institutional Review Board Statement: The study was conducted according to the guidelines of the Declaration of Helsinki and approved by the Southern Adelaide Human Clinical Research Ethics Committee (SAHREC) no. 64.19 on 9 August 2019.

Informed Consent Statement: Written informed consent was obtained from all subjects involved in the study.

Data Availability Statement: The data presented in this study are available on request from the corresponding author only after permission is granted by the ethics committee.

Conflicts of Interest: The authors declare no conflict of interest.

\section{References}

1. Clegg, A.; Young, J.; Iliffe, S.; Rikkert, M.O.; Rockwood, K. Frailty in elderly people. Lancet 2013, 381, 752-762. [CrossRef]

2. Morley, J.E.; Vellas, B.; Van Kan, G.A.; Anker, S.D.; Bauer, J.M.; Bernabei, R.; Cesari, M.; Chumlea, W.; Doehner, W.; Evans, J.; et al. Frailty Consensus: A Call to Action. J. Am. Med Dir. Assoc. 2013, 14, 392-397. [CrossRef]

3. Hammami, S.; Zarrouk, A.; Piron, C.; Almas, I.; Sakly, N.; Latteur, V. Prevalence and factors associated with frailty in hospitalized older patients. BMC Geriatr. 2020, 20, 144-148. [CrossRef] [PubMed]

4. Ibrahim, K.; Howson, F.F.A.; Culliford, D.J.; Sayer, A.A.; Roberts, H.C. The feasibility of assessing frailty and sarcopenia in hospitalised older people: A comparison of commonly used tools. BMC Geriatr. 2019, 19, 1-7. [CrossRef]

5. Artaza-Artabe, I.; Sáez-López, P.; Sánchez-Hernández, N.; Fernández-Gutierrez, N.; Malafarina, V. The relationship between nutrition and frailty: Effects of protein intake, nutritional supplementation, vitamin D and exercise on muscle metabolism in the elderly. A systematic review. Matur. 2016, 93, 89-99. [CrossRef] [PubMed] 
6. Raynaud-Simon, A.; Lesourd, B. Dénutrition du sujet âgé. Conséquences cliniques [Malnutrition in the elderly. Clinical conse-quences]. Presse Med. 2000, 29, 2183-2190.

7. Semba, R.D.; Bartali, B.; Zhou, J.; Blaum, C.; Ko, C.-W.; Fried, L.P. Low Serum Micronutrient Concentrations Predict Frailty Among Older Women Living in the Community. J. Gerontol. Ser. A Boil. Sci. Med. Sci. 2006, 61, 594-599. [CrossRef] [PubMed]

8. Takisawa, S.; Funakoshi, T.; Yatsu, T.; Nagata, K.; Aigaki, T.; Machida, S.; Ishigami, A. Vitamin C deficiency causes muscle atrophy and a deterioration in physical performance. Sci. Rep. 2019, 9, 1-10. [CrossRef]

9. Saito, K.; Yokoyama, T.; Yoshida, H.; Kim, H.; Shimada, H.; Yoshida, Y.; Iwasa, H.; Shimizu, Y.; Kondo, Y.; Handa, S.; et al. A Significant Relationship between Plasma Vitamin C Concentration and Physical Performance among Japanese Elderly Women. J. Gerontol. Ser. A Biol. Sci. Med. Sci. 2012, 67, 295-301. [CrossRef]

10. Scholz, S.S.; Borgstedt, R.; Ebeling, N.; Menzel, L.C.; Jansen, G.; Rehberg, S. Mortality in septic patients treated with vitamin C: A systematic meta-analysis. Crit. Care 2021, 25, 1-10. [CrossRef]

11. Perna, S.; Francis, M.D.; Bologna, C.; Moncaglieri, F.; Riva, A.; Morazzoni, P.; Allegrini, P.; Isu, A.; Vigo, B.; Guerriero, F.; et al. Performance of Edmonton Frail Scale on frailty assessment: Its association with multi-dimensional geriatric conditions assessed with specific screening tools. BMC Geriatr. 2017, 17, 1-8. [CrossRef]

12. Dent, E.; Kowal, P.; Hoogendijk, E.O. Frailty measurement in research and clinical practice: A review. Eur. J. Intern. Med. 2016, 31, 3-10. [CrossRef] [PubMed]

13. Frenkel, W.J.; Jongerius, E.J.; Uitert, M.J.M.-V.; Van Munster, B.C.; De Rooij, S.E. Validation of the Charlson Comorbidity Index in Acutely Hospitalized Elderly Adults: A Prospective Cohort Study. J. Am. Geriatr. Soc. 2014, 62, 342-346. [CrossRef] [PubMed]

14. Murray, S.B.; Bates, D.W.; Ngo, L.; Ufberg, J.W.; Shapiro, N.I. Charlson Index Is Associated with One-year Mortality in Emergency Department Patients with Suspected Infection. Acad. Emerg. Med. 2006, 13, 530-536. [CrossRef]

15. De Villar, L.O.-P.; Martínez-Olmos, F.J.; Junqué-Jiménez, A.; Amer-Cuenca, J.J.; Gramage, J.M.; Mercer, T.; Segura-Ortí, E. Testretest reliability and minimal detectable change scores for the short physical performance battery, one-legged standing test and timed up and go test in patients undergoing hemodialysis. PLoS ONE 2018, 13, e0201035. [CrossRef]

16. Larsson, P.; Borge, C.R.; Nygren-Bonnier, M.; Lerdal, A.; Edvardsen, A. An evaluation of the short physical performance battery following pulmonary rehabilitation in patients with chronic obstructive pulmonary disease. BMC Res. Notes 2018, 11, 1-7. [CrossRef]

17. Nightingale, C.J.; Mitchell, S.N.; Butterfield, S.A. Validation of the Timed Up and Go Test for Assessing Balance Variables in Adults Aged 65 and Older. J. Aging Phys. Act. 2019, 27, 230-233. [CrossRef] [PubMed]

18. Shumway-Cook, A.; Brauer, S.; Woollacott, M. Predicting the Probability for Falls in Community-Dwelling Older Adults Using the Timed Up \& Go Test. Phys. Ther. 2000, 80, 896-903. [CrossRef]

19. Folstein, M.F.; Robins, L.N.; Helzer, J.E. The Mini-Mental State Examination. Arch. Gen. Psychiatry 1983, 40, 812. [CrossRef]

20. Bellón, J.Á.; Lardelli, P.; Luna, J.D.D.; Delgado, A. Validity of self reported utilisation of primary health care services in an urban population in Spain. J. Epidemiol. Community Health 2000, 54, 544-551. [CrossRef]

21. Shimada, H.; Park, H.; Makizako, H.; Doi, T.; Lee, S.; Suzuki, T. Depressive symptoms and cognitive performance in older adults. J. Psychiatr. Res. 2014, 57, 149-156. [CrossRef]

22. Dennis, M.; Kadri, A.; Coffey, J. Depression in older people in the general hospital: A systematic review of screening instruments. Age Ageing 2012, 41, 148-154. [CrossRef] [PubMed]

23. Sharma, Y.; Thompson, C.; Kaambwa, B.; Shahi, R.; Miller, M. Validity of the Malnutrition Universal Screening Tool (MUST) in Australian hospitalized acutely unwell elderly patients. Asia Pac. J. Clin. Nutr. 2017, 26, 994-1000. [PubMed]

24. Balestroni, G.; Bertolotti, G. EuroQol-5D (EQ-5D): An instrument for measuring quality of life. Monaldi Arch. Chest Dis. 2012, 78, 155-159. [CrossRef] [PubMed]

25. Liu, S.K.; Montgomery, J.; Yan, Y.; Mecchella, J.N.; Bartels, S.J.; Masutani, R.; Batsis, J.A. Association Between Hospital Admission Risk Profile Score and Skilled Nursing or Acute Rehabilitation Facility Discharges in Hospitalized Older Adults. J. Am. Geriatr. Soc. 2016, 64, 2095-2100. [CrossRef] [PubMed]

26. Tessier, F.; Birlouez-Aragon, I.; Tjani, C.; Guilland, J.C. Validation of a micromethod for determining oxidized and reduced vitamin C in plasma by HPLC-fluorescence. Int. J. Vitam. Nutr. Res. 1996, 66, 166-170.

27. Mitmesser, S.H.; Ye, Q.; Evans, M.; Combs, M. Determination of plasma and leukocyte vitamin C concentrations in a randomized, double-blind, placebo-controlled trial with Ester-C®. SpringerPlus 2016, 5, 1-11. [CrossRef]

28. Johnston, C.S.; Corte, C. People with Marginal Vitamin C Status are at High Risk of Developing Vitamin C Deficiency. J. Am. Diet. Assoc. 1999, 99, 854-856. [CrossRef]

29. Nemes, S.; Jonasson, J.M.; Genell, A.; Steineck, G. Bias in odds ratios by logistic regression modelling and sample size. BMC Med. Res. Methodol. 2009, 9, 56. [CrossRef] [PubMed]

30. Sharma, Y.; Miller, M.; Shahi, R.; Doyle, A.; Horwood, C.; Hakendorf, P.; Thompson, C. Vitamin C deficiency in Australian hospitalized patients: An observational study. Intern. Med. J. 2018. [CrossRef]

31. Ravindran, P.; Wiltshire, S.; Das, K.; Wilson, R.B. Vitamin C deficiency in an Australian cohort of metropolitan surgical patients. Pathology 2018, 50, 654-658. [CrossRef] [PubMed]

32. McCall, S.J.; Clark, A.B.; Luben, R.N.; Wareham, N.J.; Khaw, K.-T.; Myint, P.K. Plasma Vitamin C Levels: Risk Factors for Deficiency and Association with Self-Reported Functional Health in the European Prospective Investigation into Cancer-Norfolk. Nutrients 2019, 11, 1552. [CrossRef] [PubMed] 
33. Carr, A.C.; Rowe, S. Factors Affecting Vitamin C Status and Prevalence of Deficiency: A Global Health Perspective. Nutrients 2020, 12, 1963. [CrossRef]

34. Jacques, P.F.; Felson, D.T.; Tucker, K.L.; Mahnken, B.; Wilson, P.W.; Rosenberg, I.H.; Rush, D. Plasma 25-hydroxyvitamin D and its determinants in an elderly population sample. Am. J. Clin. Nutr. 1997, 66, 929-936. [CrossRef]

35. Maras, J.E.; Bermudez, O.I.; Qiao, N.; Bakun, P.J.; Boody-Alter, E.L.; Tucker, K.L. Intake of $\alpha$-tocopherol is limited among US adults. J. Am. Diet. Assoc. 2004, 104, 567-575. [CrossRef]

36. Wright, J.D.; Bialostosky, K.; Gunter, E.W.; Carroll, M.D.; Najjar, M.F.; A Bowman, B.; Johnson, C.L. Blood folate and vitamin B12: United States, 1988-94. Vital-Health Stat. Ser. 11 Data Natl. Health Surv. 1998, 11, 1-78.

37. Nowjack-Raymer, R.; Sheiham, A. Association of edentulism and diet and nutrition in US adults. J. Dent. Res. 2003, 82, 123-126. [CrossRef] [PubMed]

38. Michelon, E.; Blaum, C.; Semba, R.D.; Xue, Q.L.; Ricks, M.O.; Fried, L.P. Vitamin and carotenoid status in older women: Associations with the frailty syndrome. J. Gerontol. A Biol. Sci. Med. Sci. 2006, 61, 600-607. [CrossRef] [PubMed]

39. Sanford, A.M. Anorexia of aging and its role for frailty. Curr. Opin. Clin. Nutr. Metab. Care 2017, 20, 54-60. [CrossRef]

40. Ter Borg, S.; Verlaan, S.; Hemsworth, J.; Mijnarends, D.M.; Schols, J.M.G.A.; Luiking, Y.C.; De Groot, L.C.P.G.M. Micronutrient intakes and potential inadequacies of community-dwelling older adults: A systematic review. Br. J. Nutr. 2015, 113, 1195-1206. [CrossRef] [PubMed]

41. Saum, K.-U.; Dieffenbach, A.K.; Jansen, E.H.; Schöttker, B.; Holleczek, B.; Hauer, K.; Brenner, H. Association between Oxidative Stress and Frailty in an Elderly German Population: Results from the ESTHER Cohort Study. Gerontology 2015, 61, 407-415. [CrossRef] [PubMed]

42. Moylan, J.S.; Reid, M.B. Oxidative stress, chronic disease, and muscle wasting. Muscle Nerve 2007, 35, 411-429. [CrossRef]

43. Arbogast, S.; Reid, M.B. Oxidant activity in skeletal muscle fibers is influenced by temperature, $\mathrm{CO} 2$ level, and muscle-derived nitric oxide. Am. J. Physiol. Integr. Comp. Physiol. 2004, 287, R698-R705. [CrossRef]

44. Winterbourn, C.C. Reconciling the chemistry and biology of reactive oxygen species. Nat. Chem. Biol. 2008, 4, 278-286. [CrossRef]

45. Kondo, H.; Nakagaki, I.; Sasaki, S.; Hori, S.; Itokawa, Y. Mechanism of oxidative stress in skeletal muscle atrophied by immobilization. Am. J. Physiol. Metab. 1993, 265, E839-E844. [CrossRef]

46. Rodríguez-Hernández, Á.; Cordero, M.D.; Salviati, L.; Artuch, R.; Pineda, M.; Briones, P.; Izquierdo, L.G.; Cotán, D.; Navas, P.; Sánchez-Alcázar, J.A. Coenzyme Q deficiency triggers mitochondria degradation by mitophagy. Autophagy 2009, 5, 19-32. [CrossRef]

47. Siu, P.M.; Pistilli, E.E.; Alway, S.E. Age-dependent increase in oxidative stress in gastrocnemius muscle with unloading. J. Appl. Physiol. 2008, 105, 1695-1705. [CrossRef]

48. Lewis, L.N.; Hayhoe, R.P.G.; A Mulligan, A.; Luben, R.N.; Khaw, K.-T.; A Welch, A. Lower Dietary and Circulating Vitamin C in Middle- and Older-Aged Men and Women Are Associated with Lower Estimated Skeletal Muscle Mass. J. Nutr. 2020, 150, 2789-2798. [CrossRef] [PubMed]

49. Chapman, M.; Meza, R.; Lieber, R.L. Skeletal muscle fibroblasts in health and disease. Differentiation 2016, 92, 108-115. [CrossRef] [PubMed]

50. Rebouche, C.J. Ascorbic acid and carnitine biosynthesis. Am. J. Clin. Nutr. 1991, 54, 1147S-1152S. [CrossRef] [PubMed]

51. Barreiro, E.; de la Puente, B.; Busquets, S.; López-Soriano, F.J.; Gea, J.; Argiles, J.M. Both oxidative and nitrosative stress are associated with muscle wasting in tumour-bearing rats. FEBS Lett. 2005, 579, 1646-1652. [CrossRef]

52. Martin, H.; Sayer, A.A.; Jameson, K.; Syddall, H.; Dennison, E.M.; Cooper, C.; Robinson, S. Does diet influence physical performance in community-dwelling older people? Findings from the Hertfordshire Cohort Study. Age Ageing 2011, 40, 181-186. [CrossRef]

53. Fung, T.; Stuijk, E.; Rodriguez-Artalejo, F.; Hagan, K.; Hu, F.; Lopez-Garcia, E. Fruits and Vegetables Intake and Risk of Frailty in Women Aged 60 and Older (OR33-08-19). Curr. Dev. Nutr. 2019, 3. [CrossRef]

54. Zhu, F.; Du, B.; Xu, B. Anti-inflammatory effects of phytochemicals from fruits, vegetables, and food legumes: A review. Crit. Rev. Food Sci. Nutr. 2018, 58, 1260-1270. [CrossRef]

55. Zhao, C.-N.; Meng, X.; Li, Y.; Li, S.; Liu, Q.; Tang, G.-Y.; Li, H.-B. Fruits for Prevention and Treatment of Cardiovascular Diseases. Nutrients 2017, 9, 598. [CrossRef]

56. Wang, X.; Ouyang, Y.; Liu, J.; Zhu, M.; Zhao, G.; Bao, W.; Hu, F.B. Fruit and vegetable consumption and mortality from all causes, cardiovascular disease, and cancer: Systematic review and dose-response meta-analysis of prospective cohort studies. BMJ 2014, 349, g4490. [CrossRef] [PubMed]

57. Cook, N.R. A Randomized Factorial Trial of Vitamins C and E and Beta Carotene in the Secondary Prevention of Cardiovascular Events in Women. Arch. Intern. Med. 2007, 167, 1610-1618. [CrossRef]

58. Loria, C.M.; Klag, M.J.; E Caulfield, L.; Whelton, P.K. Vitamin C status and mortality in US adults. Am. J. Clin. Nutr. 2000, 72, 139-145. [CrossRef] [PubMed]

59. Ashor, A.W.; Brown, R.; Keenan, P.D.; Willis, N.D.; Siervo, M.; Mathers, J.C. Limited evidence for a beneficial effect of vitamin C supplementation on biomarkers of cardiovascular diseases: An umbrella review of systematic reviews and meta-analyses. Nutr. Res. 2019, 61, 1-12. [CrossRef] 
60. Allard, J.P.; Keller, H.; Teterina, A.; Jeejeebhoy, K.N.; Laporte, M.; Duerksen, D.R.; Gramlich, L.; Payette, H.; Bernier, P.; Davidson, B.; et al. Factors associated with nutritional decline in hospitalised medical and surgical patients admitted for $7 \mathrm{~d}$ or more: A prospective cohort study. Br. J. Nutr. 2015, 114, 1612-1622. [CrossRef]

61. Lima, J.; Teixeira, P.P.; Eckert, I.D.C.; Burgel, C.F.; Silva, F.M. Decline of nutritional status in the first week of hospitalisation predicts longer length of stay and hospital readmission during 6-month follow-up. Br. J. Nutr. 2021, 125, 1132-1139. [CrossRef] [PubMed] 